\title{
Article \\ The Influence of a Brand's Visual Content on Consumer Trust in Social Media Community Groups
}

\author{
Lukas Karpenka $^{1}$, Elzè Rudienè ${ }^{1}$, Mangirdas Morkunas ${ }^{2, *}$ and Artiom Volkov ${ }^{3}$ (D) \\ 1 Business School, Vilnius University, Sauletekio Avenue 22, 01513 Vilnius, Lithuania; \\ lukas.karpenka@gmail.com (L.K.); elze.rudiene@vm.vu.lt (E.R.) \\ 2 Faculty of Economics and Business Administration, Vilnius University, Sauletekio Avenue 9, \\ 01513 Vilnius, Lithuania \\ 3 Institute of Economics and Rural Development, Lithuanian Social Research Center, A. Vivulskio Street 4A-13, \\ 01108 Vilnius, Lithuania; artiom.volkov@laei.lt \\ * Correspondence: mangirdas.morkunas@evaf.vu.lt
}

Citation: Karpenka, L.; Rudienė, E.; Morkunas, M.; Volkov, A. The Influence of a Brand's Visual Content on Consumer Trust in Social Media Community Groups. J. Theor. Appl. Electron. Commer. Res. 2021, 16 , 2424-2441. https://doi.org/10.3390/ jtaer16060133

Academic Editor:

Subir Bandyopadhyay

Received: 2 August 2021

Accepted: 8 September 2021

Published: 17 September 2021

Publisher's Note: MDPI stays neutral with regard to jurisdictional claims in published maps and institutional affiliations.

Copyright: (C) 2021 by the authors Licensee MDPI, Basel, Switzerland This article is an open access article distributed under the terms and conditions of the Creative Commons Attribution (CC BY) license (https:// creativecommons.org/licenses/by/ $4.0 /)$

\begin{abstract}
The study covered by the present paper sought to look into a range of factors affecting the building of trust in brands among social media community groups. For the purpose of the present study, in order to measure the influence of visual content, the authors of the present paper investigated its visual as well as emotional characteristics while factoring in consumer engagement variables. In order to test our hypotheses, two different visual advertisements of an artificial hypothetical apparel brand were created. The robustness of the results was ensured by the findings of the representative consumer survey and a factor and regression analysis. The survey concluded that engagement with the brand-created content by social media community groups may be viewed as a proxy variable when studying the consumer confidence in a brand within consumer groups. The authors of the paper also argue that an image-based content identity does affect the engagement with the content created by a brand within the social network community groups. The difference impact of the cognitive, emotional or behavioral involvement of social media community group members onto the formation of brand trust is revealed.
\end{abstract}

Keywords: consumer trust; social media community groups; video content

\section{Introduction}

Social media community groups (SMCG) are an ever-growing platform for opinionsharing, enhanced discussions and advice [1,2]. On the major social media platforms, the SMCG are referred to almost identically and perceived as providing comparable functionality. Among the most popular of such groups are Facebook Groups, Twitter Chat and LinkedIn Groups. Focusing on specific subject matters brings together consumers of similar interests that are interested in and willing to engage with the content [3]. In addition to being involved in a range of discussions and advice, the users in their respective groups look for goods to sell or buy and check out for different promotions [4]. SMCGs also expose particular behavioral qualities, such as satisfaction-driven engagement with the content created by the community, and boosting one's self-confidence through belonging to an SMCG [1]. Social media community groups are a highly relevant channel for trade marks [5] and all the more so currently in the view of an increasingly personalized communication with consumers [6] and increasing competition, leading to communication expenses in 2014-2019 to have more than doubled [7]. One of the most outstanding traits of the mass communication channel is the high-level confidence in their members and their content $[8,9]$, thus creating media conducive to gaining strength by brands taking advantage of the communication channels available within the groups. The confidence in a trade mark concept can be defined as meeting of the customer expectations that a brand will perform as promised [10]. 
Image-based content in the form of pictures and video clips are the most frequent form of content used by trade marks [11]. Image-based content is popular due to its ability to attract consumer attention and to facilitate engagement; as many as $94 \%$ of consumers prefer image-based content to text-based content [12]. On social media, brands mostly seek to build meaningful relations with consumers regarding the benefits and image formation over a long-term period [13]. Furthermore, it should be noted that brand image-based content is heavily focused on consumer satisfaction; therefore, its development is related to psychological aspects. From the consumer's point of view, confidence attached to the procuring process is an important factor that may potentially affect the shopping intentions; in this relation, it is important to find out whether or not the image-based content created by a brand within social media community groups can affect consumer confidence.

The social media community groups operate as a forum facilitating building a dialogue with potential consumers and attracting interest in the brand [14]. While developing the technical features of the groups, such as segmentation and filtering of the information at the same time, especially focusing the information flow to the subject most relevant to consumerse [15], such groups continue to remain important communication channels for brands, specifically focused on personalization. Although social media community groups were earlier noted as possible communication channels, only few authors in the research literature have noted the preferred direction of the content created therein, and its possible effect on consumers. Sources in the research literature claim that the content posted in the groups has a potential to change consumer attitude towards the brand and prompt them to buy producers goods [8]; however, the content has to be adjusted to the context of the group [14]. Researchers consider that the brand-created content may cause consumer confidence [15], but due to an absence of solid empirical evidence, the specific attributes that the content has to reflect remains uncertain. Seeking to fill the research gap, the present paper sought to identify the features of the brand-developed content that are vital in building consumer trust in brands in social media community groups.

This study is also relevant from an empirical aspect: today, brands need to be as close to the consumer as possible to build consumer trust. This study helps to clarify what kind of visual content could build consumer trust in social media community groups. Our research also provides insights of the type of engagement (cognitive, emotional or behavioral involvement) that can be expected and influent on consumer trust.

This study contributes social media community groups researches represented by Davis, Piven \& Breazeale [16], Myrick et al. [17] and Sirola et al. [18], enriching it by providing insights on the content and visual aspects which promote brand trust.

The present paper consists of a literature review that provides a theoretical background for the study, followed by a methodological part that presents a context for the research hypotheses and the research design. Next, the results section introduces the main findings and the conclusion section generalizes the outcomes and provides future research directions.

\section{Literature Review}

The theoretical background of this research is split into two parts. First, the influence of a brand's visual information on the formation of trust and brand trust is presented. It also contains an overview of trust on social media. Secondly, we introduce attributes which affect consumer trust in social media community groups.

\subsection{The Link between a Brand's Visual Information and the Trust and Brand Trust in Social Media Community Groups}

It is a fact that image-based content can affect consumer confidence in social media groups [19]. This conclusion was derived from the findings of comparable studies and the analysis of research literature, when the assessment of the efficiency of the imagebased content targets engagement. Engagement is considered to be a manifestation of the band and can consist of three parts: cognitive, emotional and behavioral [20]. When considering what could motivate consumers to engage with content, certain elements, 
such as informativeness and quality, fun/entertainment attractiveness and identity, may be considered playing important roles in boosting confidence $[9,21]$. Both the confidenceboosting elements and engagement manifestation have qualities similar to the merging dimension of virtual communities, which is manifested by comprehensive engagement of the consumer with the content and the 'flow' conditions, and arise from the satisfaction with the content [22]. The confidence-boosting components can be fulfilled by referring to the efficient image-based content characteristics defined by Okoli [23] (attractiveness, comprehensibility and memorability), which encourage the consumer to buy the brand's products, and mostly encompass the technical image-based content qualities.

It has been proven that the content created for social media by brands may have direct effects on consumer confidence [24]. Any brand on social media has abundant freedom and opportunities to prompt the consumer to buy their products, and naturally, brand confidence may arise [25]. Although social media and networks create ambient space for creativity, Kim and Ahmad [26] concluded that earning consumer confidence on social media is a challenging task, as a lack of trust is subjective and ordinarily arises from personal experience. Personal experiences have more of an impact on brand trust than the opinion of other consumers, whether positive or negative. Even a very small number negative experiences can discourage consumers to buy products from the brand, and on the contrary, a small number of positive experiences and an attractive image in society can build a bridge towards confidence. A number of authors have noticed that consumers normally tend to avoid extremes; additionally, since consumers may initially treat a brand with a good portion of skepticism, some negative experiences may develop into mistrust. With that knowledge at hand, it can be said that it all depends on the brand itself and whether it will be able to provide the consumer with a positive experience that would lead to consumer trust.

The differing aspects arising in building trust in social media community groups and in perspective of separate persons were mentioned by Kang [27]. Brand trust, which is considered to be a proxy for customer loyalty, is seen as a component of the relationship set within the community groups [28]. Going further, Habibi, Laroche \& Richard [29] emphasized the community relationship and established roles in building brand trust. Jibril et al. [30], however, diminished the role of brand trust in favor of brand loyalty in community groups, considering it to be only one part of the customer loyalty puzzle. Santos, Coelho \& Rita (2021) [31] focused on consumer engagement as a focal factor in creating brand trust in social media groups. Trust transfer mechanisms within social media community groups and their role in building trust in a brand was the focus of the research by Wang et al. [32]. This study enhanced the investigation by Liu et al. [20], which concluded that engagement of consumers with social media content affects confidence in brands. The authors approached the consumer engagement from a psychological viewpoint, consisting of three components, i.e., cognitive engagement, emotional engagement and engagement behavior. Liu et al. [20] studied consumer confidence in brands on community social media, and distinguished two situations that can facilitate building confidence. The first situation, $\mathrm{C} 2 \mathrm{C}$, realizes itself through communication with other members of the community. Confidence among consumers develops by sharing personal information, interests and mutual recognition. The second situation, $\mathrm{C} 2 \mathrm{M}$, develops when the consumer communicates with the persons responsible for the creation of the content and its placement for the community. The representatives of the brand who place the content on social media or the moderators communicate with consumers not only from material motives, they sometimes may also engage in emotional conversation. It has been noticed, however, that in both cases, the essential attributes affecting confidence in a brand within the social media community groups remain the same [33]. Such attributes are further discussed in the following subsection.

\subsection{The Attributes Affecting Confidence in a Brand within Social Media Community Groups}

Consumers define fairly high requirements with respect to the content due to the large amount of information on the Internet and the ability to create quality content them- 
selves [23]. A highly IT-literate audience can immediately spot unpolished content, and can immediately skip it and lose interest; therefore, according to Zailistaitè-Jakšte [34], brands should elaborate the content and adapt it in order to boost engagement and strengthen the brand.

A number of authors [13,23,35] have identified individual image attributes that build the content of the image on social media. Objective, design, understandability and memorability were identified as a result of numerous studies on image-based content, both from a technical viewpoint as well as the benefit to consumers and the brands. The purpose of image-based content includes the purposes of the content of the brand created on social media, as identified by Kim, Spiller and Hettche [13]: task-focused, engagement-focused and self-focused. Such objectives select the overall direction, themes of the content and whether the content is an image text. Task-focused content is to a much larger extent focused on sales, rather than the efficiency or attractiveness of the content. Various discount and voucher communications are among the examples of this type of content. By employing engagement-driven content, a brand seeks to present to the viewer interesting and useful content that would facilitate the building of a connection. This content also includes a number of factors that are not directly related to the brand, such as information, opinion, views, entertainment and questions to the audience. The purpose of a piece of content has the same characteristics as a member of the STBG, such as communicating as personally as possible, presenting current affairs or content of general interest. Selfcantered purpose conveys only brand-related information and is not very engaging or interesting to a common consumer. The content attributable to this purpose includes brand stories, news, event information and team presentations. Dunay and Krueger [36] argued that the STBG brand should avoid content about itself because consumers may view it negatively. Of the three goals, the two most relevant were engagement-focused and task-focused goals. The characteristics of image-based content design include the technical elements of image-based content. Some of these elements were described in the studies by Danaitis and Uscaite [35], while others were described by Okoli [23]. Image-based content design is separated from the feature of effective video content attractiveness, because in terms of its description and impact on the user, it overlaps with the attractiveness and informative and quality confidence building components highlighted by Lou and Yuan [9]; the latter components are contained in the second block of the model. Additionally, the attractiveness described by Okoli [23] has variables that partly overlap with other distinguished characteristics; these characteristics may be independent of the characteristics of the brand itself, such as popularity. The components of image-based content are: color, graphic elements, composition, ease of sharing and visual storytelling. The latter two characteristics are relatively narrow. The first one is the understandability of image-based content. Okoli [23] pointed out one specific attribute and function of efficient image-based content, namely its ability to describe the use of photographic images and illustrations and highlight, substantiate and supplement the fundamental information of the content, so that both the image and the text are mutually related. The second quality, the memorability of image-based content, is considerably more abstract and is based on clarity and ease of memorization. The most important parts here are the connection between the images and information (as we understand it) and the positive emotion of the user seeing the image-based content.

Some additional theoretical insights $[9,21]$ focus on the different factors that affect image confidence on social media, such as quality and informativeness, joyfulness, attractiveness and identity. Out of all triggers of trust in brands, these were designated as being the most suitable for social network communication, as the other ones either cannot be realized by the brand itself or are more related to the further steps in the procurement process. The quality and informativeness factor include things such as novelty of the information, professionalism in presentation, credibility and effectiveness. This factor is specifically related to the consumer's view whether or not the information is useful and properly presented. The joyfulness factor captures the ability to trigger interest of the 
consumer in receiving information from the brand and being entertained. Attractiveness includes design elements and the beauty of the image-based content perceived by the consumer. The identity factor describes the closeness of the social media content created by the brand to the audience through interests, demography and ideology. The identity factor also encompasses one more factor singled out by Jakic et al. [37] — brand speaking tone/style. The speaking tone/style defines the consistency of the vocabulary and speaking manner to the specific consumer segments.

It has been generally acknowledged that consumer involvement in the creation of brand content is one of the factors for building consumer trust in various brands [29,38-40]. This engagement with the content created within social media community groups by a brand describes consumer involvement methods: cognitive engagement, emotional engagement and engagement though behavior [20]. Cognitive engagement describes the functional motives of the consumer, the consumer's desire to take interest in a brand, its goods and qualities, exclusivity, technical parameters). Emotional engagement is about using positive emotions to convince the consumer to want more content from the brand. The consumer has certain preferences with respect to the content, such as content that is entertaining, joyful, distracting them from their daily routine and relaxing. Such engagement by behavior describes specific actions of the user, such as communication, commenting, responding, subscriptions, feedback, positive feedback about the brand and consumer advice regarding the brand [15]. The results of such engagement are best visible for the brand even without studies. All the three engagement methods essentially mean consumer confidence in a brand. With at least one type of engagement present, the consumer already starts showing confidence, which grows in strength with each new engagement. This is the path to building consumer confidence in a brand; in essence, it means ultimate confidence on part of the consumer in a brand through image-based content created within social media community groups.

\section{Materials and Methods}

This section focuses on the research methodology, and consists of the context of the study and the justification of the assumptions, selecting and substantiating the test hypotheses and the questionary survey to substantiate the mutual influence of the variables within the social network.

\subsection{Context of the Study and the Justification of the Assumptions}

A detailed analysis of the impact of image-based content created by a brand to enhance consumer confidence within SMCGs showed that in general, information or studies related to SMCG are rather scarce. In most cases, information was not sufficiently specified to provide an interpretation of a specific situation, where the study rather offered a broader approach focusing on the use of the overall use of image-based content on social media. Image-based content is examined in terms of its potential effects or benefit to the consumer and the brand, as well as its technical parameters.

An overview of studies on SMCGs led to the conclusion that the groups are only to a very limited extent examined from the viewpoint of image-based content and confidence in a brand, the gap being filled by theories based on studies of social networks, image-based content, brands, engagement and SMCGs in the most general sense. As a result, any study of the impact of image-based content created by the brand in social media community groups has to be based on the individual features of the most relevant components and the level of knowledge about them. Table 1, presented below, summarizes the studies and analyses dominant in the area of studies of SMCGs, the content of social media, image-based content as well as the context of confidence and engagement. 
Table 1. SMCG, social networks and brand content, video content, confidence and involvement contexts.

\begin{tabular}{|c|c|}
\hline Author, Year & Context of the Study \\
\hline Kim, Spiller and Hettche [13] & $\begin{array}{l}\text { The survey was conducted on the social network Facebook, involved studying the } \\
\text { content of the brand social networks, its formats: textual, pictures and video clips. }\end{array}$ \\
\hline Okoli [23] & $\begin{array}{l}\text { The survey was focused on social networks in the most general sense and analysed } \\
\text { video clips as a video content form. }\end{array}$ \\
\hline Danaitis and Usovaitè [35] & Analysis of the graphic and creative aspects of video content. \\
\hline Lou and Yuan [9] & $\begin{array}{l}\text { The survey focused upon the impact of social media influencers upon consumers; } \\
\text { the aspects examined content informativeness, credibility, attractiveness, identity, } \\
\text { brand awareness and purchase intentions. }\end{array}$ \\
\hline Harridge-March [21] & $\begin{array}{l}\text { The survey focused on consumers in electronic commerce while studying } \\
\text { consumer confidence and the perceived risks. }\end{array}$ \\
\hline Liu et al. [20] & $\begin{array}{l}\text { The survey mainly focused on confidence in the brand; possibilities to transpose } \\
\text { the confidence in brands to the social media brand communities. }\end{array}$ \\
\hline Koh et al. [22] & $\begin{array}{l}\text { The study focused on the behaviour of members of virtual communities; } \\
\text { community spirit, virtual community leaders, live member meetings, satisfaction } \\
\text { with community content. }\end{array}$ \\
\hline
\end{tabular}

The study was conducted in a variety of contexts, but with regards to social networks, they were more focused on Facebook or relied more on data from Facebook, mainly because Facebook is the market giant and, according to Statista [41], has the largest number of users among a range of other social networks-more than 2.5 billion. If compared to other social networks, such as Twitter, which has more than 350 million users, or LinkedIn with 645 million (Statista [41], Facebook is the most conducive platform for brands to communicate with consumers. Furthermore, Facebook and the STBGs operating on its platform enjoy large memberships and verified functionalities to create content, facilitating the brand to establish a more personal contact with the consumer, which is the current trend on the market [6]. Thus, Facebook was selected by the authors of the present paper as the context of the study, specifically focusing on the social media community groups active on this platform.

In order to determine the potential impact of the video content on consumer confidence in social media community groups and to fill gaps in the scientific literature, the survey raised six main hypotheses (H1-H6) and several additional hypotheses (a-d) (Table 2).

Table 2. Hypotheses for an empirical study of the influence of the video content created by a brand on consumer confidence in social media community groups.

\begin{tabular}{|c|c|}
\hline esis & Summary and Justification \\
\hline $\begin{array}{l}\text { (H1) The characteristics of video content affect the drivers of consumer } \\
\text { confidence in the brand } \\
\text { (H1a) The characteristics of video content affect the quality and the } \\
\text { informativeness of the video content } \\
\text { (H1b) The characteristics of video content affect its entertainment } \\
\text { qualities } \\
\text { (H1c) The characteristics of video content affect its attractiveness }\end{array}$ & $\begin{array}{l}\text { Hypothesis H1 seeks to identify the confidence drivers that can be } \\
\text { reflected by the video image created by a brand within social media } \\
\text { community groups. Since there are total four confidence drivers, } \\
\text { hypothesis H1 distinguished four additional partial hypotheses (a, b, c, } \\
\text { and d) that specifically define the boundaries of the study of the } \\
\text { possible influence of video content characteristics on each confidence } \\
\text { driver. Seeking to mitigate the complexity of the task, the video content } \\
\text { characteristics were assessed as a single variable that due to its entirety } \\
\text { that encompasses the purpose of the content, its design, } \\
\text { comprehensibility, and memorability, could affect the consumer } \\
\text { confidence drivers and the overall trust in a brand. This hypothesis } \\
\text { arises from the sources in research literature }\end{array}$ \\
\hline
\end{tabular}


Table 2. Cont

\begin{tabular}{|c|c|}
\hline Hypothesis & Summary and Justification \\
\hline $\begin{array}{l}\text { (H2) The quality and the informativeness of the video content affect the } \\
\text { involvement of the content created by a brand within the social network } \\
\text { community groups. } \\
\text { (H2a) The quality and the informativeness of the video content affect } \\
\text { the cognitive involvement } \\
\text { (H2b) The quality and the informativeness of the video content affect } \\
\text { the emotional involvement } \\
\text { (H2c) The quality and the informativeness of the video content affect the } \\
\text { behavioural involvement } \\
\text { (H3) The fun of the video content affects the involvement in the content } \\
\text { created by a brand within the social network community groups. } \\
\text { (H3a) The fun of the video content affects the cognitive involvement } \\
\text { (H3b) The fun of video content affects the emotional involvement } \\
\text { (H3c) The fun of the video content affects the behavioural involvement } \\
\text { (H4) The attractiveness of the video content affects the involvement in } \\
\text { the content created by a brand within the social network community } \\
\text { groups. } \\
\text { (H4a) The attractiveness of the video content affects the cognitive } \\
\text { involvement } \\
\text { (H4b) The attractiveness of the video content affects the emotional } \\
\text { involvement } \\
\text { (H4c) The fun of the video content affects the behavioural involvement } \\
\text { (H5) The identity of the video content affects the involvement in the } \\
\text { content created by a brand within the social network community } \\
\text { groups. } \\
\text { (H5a) The identity of the video content affects the cognitive involvement } \\
\text { (H5b) The identity of the video content affects the emotional } \\
\text { involvement } \\
\text { (H5c) The identity of the video content affects the behavioural } \\
\text { involvement } \\
\text { (H6) Involvement in the video content created by a brand within social } \\
\text { media community groups affect the confidence in the brand }\end{array}$ & $\begin{array}{l}\text { The H2-H5 hypotheses were identified to clarify whether the } \\
\text { confidence drivers can affect the consumer involvement that is } \\
\text { otherwise considered to be a manifestation of consumer confidence. } \\
\text { Since engagement consists of three variables (cognitive, emotional and } \\
\text { behavioral), the H2-H5 hypotheses have also some partial hypotheses } \\
\text { (a, b, and c) that helps identifying the effect of each confidence triggers } \\
\text { upon a specific engagement. The H2-H5 hypotheses arise from the } \\
\text { sources in research literature. The H6 hypothesis encompasses an } \\
\text { overall assessment whether or not involvement in the video content } \\
\text { created by a brand within social media community groups affect the } \\
\text { confidence in the brand The hypothesis arises from the assumption of } \\
\text { the importance of confidence in the consumer procurement process in } \\
\text { the span between the communication and the procurement, that was } \\
\text { addressed in the model designed and the studies carried out by Soni } \\
\text { and Verghese [42]. }\end{array}$ \\
\hline
\end{tabular}

An empiric study model (Figure 1) was built and designed to convey and summarize the logics underlying hypotheses H1-H6. The study model conveys four sets of constructs, providing the principal and partial hypotheses and defining the links between the variables. Such interactions show the effect and impact of the video content characteristics on the drivers of confidence and the impact of confidence drivers on the engagement.

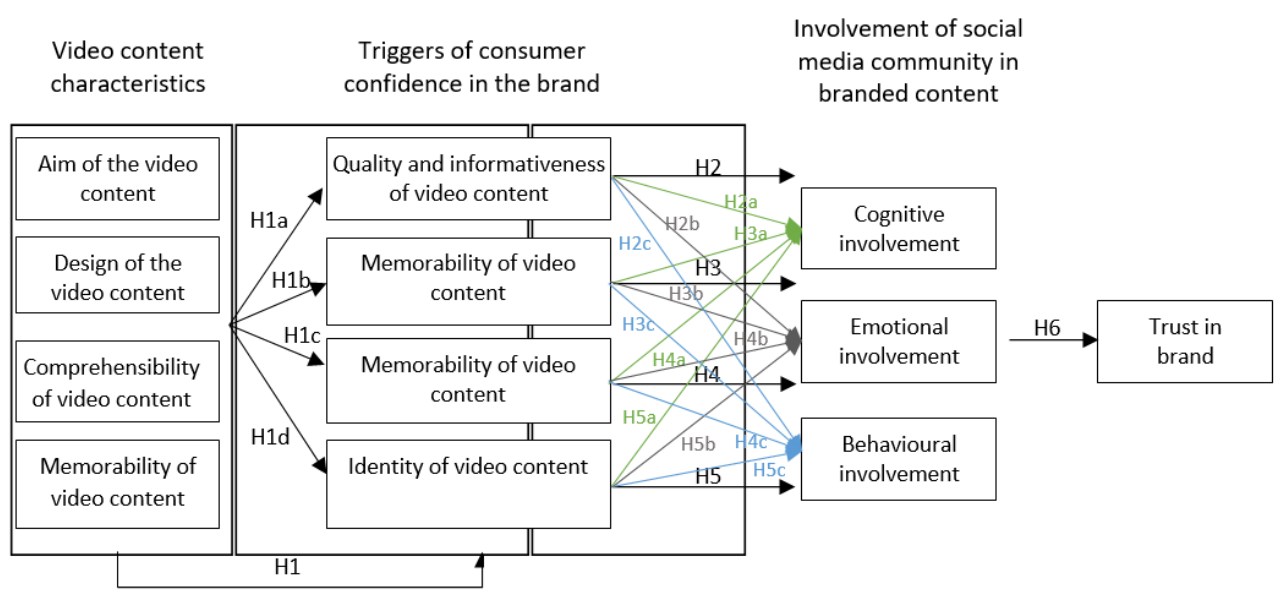

Figure 1. Model for an empirical study of the influence of the video content created by a brand on consumer confidence in social media community groups. 
Scale reliability, factor and correlation analyses are used to test hypotheses and substantiate the design of the study model. Simple and multiple regression analyses were used to determine the influence of the identified variables.

\subsection{Survey}

A questionnaire survey was conducted as part of the study and was designed to substantiate the mutual influence of the variables within Facebook community groups; the questionnaires consisted of three blocks of questions (statements):

- The assessment of the characteristics of the video content through the drivers of consumer confidence in the brand;

- The assessment of engagement with the video content through the drivers of consumer confidence in the brand;

- The assessment of confidence in the brand through the engagement with the video content created by the brand on the SMCG.

For the purpose of the study, the authors of the present paper selected two examples of video content (Figure 2) created according to the characteristics of the video content. The choice to use for the purpose of the study two examples was based on the assumption that the most efficient approach to understand the characteristics of the purpose is to split it into two rather than three sections. This relevance arise that the self-cantered content identified by Kim, Spiller and Hettche [13] with regards to the objectives pursued by social media content is relevant for the already existing or well-known brands. Since the study does not use any genuine brands, it is limited to two objectives: task-focused (sales) and engagement-focused (relation-building). Both examples of video content will refer to the situations in the apparel market, being one of the highest sale volumes sector (Statista [41], and can be easily adapted to a wide audience. With a view to provide reference to the technical parameters, characteristics and the model for the empiric study, Figure 2 provides video content examples created based on the parameters listed in Table 3.

The photos in the video content examples in Figure 2 are taken from the free photo site unsplash.com. The author of the picture used in the first example is Markus Winkler, and the second picture was created by Tom the Photographer. The graphic element used in the logo was taken from the graphic element website flaticon.com; its author is Pixel perfect.
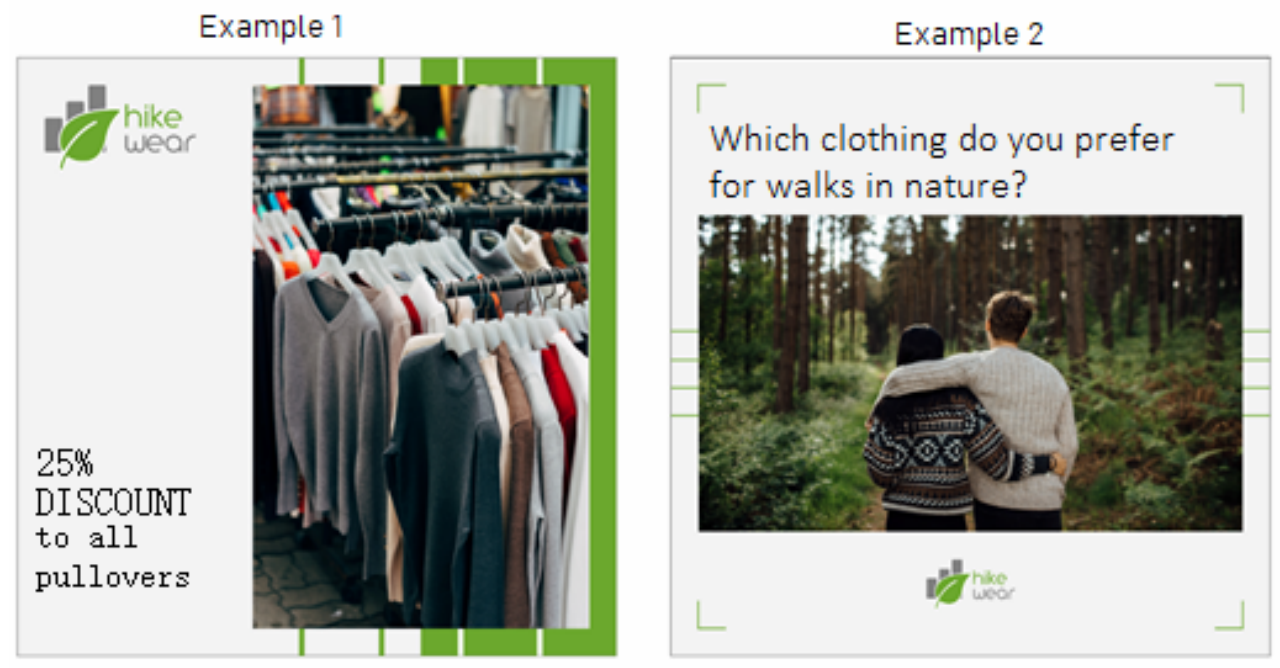

Figure 2. Video content examples used for the purpose of the empiric study. 
Table 3. Parameters for the video content examined for the empiric survey.

\begin{tabular}{|c|c|c|}
\hline & Example 1 & Example 2 \\
\hline $\begin{array}{l}\text { Objective } \\
\text { Format }\end{array}$ & $\begin{array}{l}\text { Task-focused Discount for sweaters } \\
\text { Picture }\end{array}$ & $\begin{array}{l}\text { Engagement-focused Question to SMCG members } \\
\text { Picture }\end{array}$ \\
\hline $\begin{array}{l}\text { Dominant } \\
\text { colors }\end{array}$ & \#12252B \#EEEFEE \#70D30B \#6D5E56 \#ACAFA2 & \#6F7734 \#201E12 \#A8A792 \#F0F1F0 \#44451B \\
\hline Graphic elements & $\begin{array}{c}\text { Font-lean } \\
\text { Graphic pictures-vertical lines, vertical } \\
\text { rectangle } \\
\text { Vertical picture of the apparel } \\
\text { Brand logo }\end{array}$ & $\begin{array}{c}\text { Font-lean } \\
\text { Graphic pictures-horizontal lines angles } \\
\text { Horizontal picture with people } \\
\text { Brand logo }\end{array}$ \\
\hline Composition & $\begin{array}{l}\text { Square layout } \\
\text { Asymmetrical alignment-text and graphic } \\
\text { pictures on the left, and the picture on the right }\end{array}$ & $\begin{array}{l}\text { Square layout } \\
\text { Symmetrical alignment-horizontally centered }\end{array}$ \\
\hline Easy to share & $\begin{array}{l}\text { Square form-optimal to all devices, size: } \\
\qquad 1080 \times 1080 \text { pixels }\end{array}$ & $\begin{array}{l}\text { Square form-optimal to all devices, size: } \\
\qquad 1080 \times 1080 \text { pixels }\end{array}$ \\
\hline Visual story telling & Conveyed image from the display in the store & People walking dressed in branded pullovers \\
\hline Comprehensibility & $\begin{array}{l}\text { The picture complements the provided } \\
\text { information }\end{array}$ & $\begin{array}{l}\text { The picture complements the question by illustrating } \\
\text { it }\end{array}$ \\
\hline
\end{tabular}

The questionnaire used for the purpose of the study evaluates user activity in Facebook community groups and user attitudes to brand content development at SMCG; the first example of video content (Figure 2) is being examined through three blocks of statements:

1. Assessment in terms of the four triggers of trust in a brand: video content quality and informativeness, fun of the video content, attractiveness of the video content and identity of the video content;

2. Assessment of the consumer's desire to be engaged in the brand-created video content on the SMCG, which reflects the triggers of confidence in the brand through three engagement variables: cognitive engagement, emotional engagement and engagement by behavior;

3. Provided statements designed to clarify whether or not the variables of engagement in the brand-created content in the social media community groups actually reflect confidence in the brand.

After the respondent completed the first section of the survey for the first example of the video content, the same procedure is repeated with the second example. The end of the questionnaire contains some demographic questions about the respondent's gender and age. The statements used in all units are rated according to a five-point Likert scale.

\subsection{Survey Sample and Data Analysis Methods}

According to the data provided by NapoleonCat [43], there are about 1.8 million Facebook users in Lithuania, of which, according to Statista [41], about 1.7 million are active on a monthly basis. The size of the sample was 384 for the purpose of the present survey, which was set considering the size of the general population and using the Survey Sample Calculator. The survey sample was established having selected a confidence level of $95 \%$ and a confidence interval of $5 \%$. The respondents were selected on the basis of the random convenience sampling method. The survey was conducted in December 2020. The questionnaires were circulated within the social media community groups, as well as personal virtual chat channels. Before starting to analyze the results, the reliability of the scales of the compiled questionnaire was checked using Cronbach's alpha analysis, which is based on the correlation between various questions/statements. 


\section{Results}

The results received from 387 respondents showed the following gender-based distribution: $53 \%$ males and $47 \%$ females. The age-based distribution of the respondents was fairly broad, ranging from 18 to 57 years of age. In general terms, the activity of respondents on the SMCG is fairly low, as the average number of 'like' clicks were 3.5 out of 5; however, the respondents still tended to refrain from comments (2.67) or sharing the content (2.81). The respondents assigned the lowest score, in terms of activity, to content creation (2.47).

The medium confidence rate of the statements used in the questionnaire was estimated in the data analysis stage using the Cronbach's alpha coefficients (Table 4).

Table 4. Cronbach's alpha coefficient of the confidence of the survey questionnaire.

\begin{tabular}{cc}
\hline Construct Scale & Cronbach's Alpha Value \\
\hline Video content characteristics & 0.940 \\
\hline Confidence Triggers through the Video Content (Video Content Example 1) \\
Quality and informativeness & 0.886 \\
Fun & 0.894 \\
Attractiveness & 0.924 \\
Identity & 0.921 \\
\hline Confidence Triggers through the Video Content (Video Content Example 2) \\
Quality and informativeness & 0.879 \\
Fun & 0.881 \\
Attractiveness & 0.927 \\
Identity & 0.888 \\
\hline Confidence Triggers through the Video Content (Both Video Content Examples) & 0.925 \\
Quality and informativeness & 0.910 \\
Fun & 0.932 \\
Attractiveness & 0.899 \\
Identity & \\
Engagement with Confidence Triggers & 0.936 \\
Eognitive engagement & 0.932 \\
Enotional engagement & 0.936 \\
\hline Engagement by behavior & 0.855 \\
\hline confidence & 0.921 \\
\hline Cronbach's alpha of all statements & \\
\hline
\end{tabular}

The factor analysis was carried out following the structure presented in Table 5.

Table 5. Results of the factor analysis of the video characteristics.

\begin{tabular}{cc}
\hline Factors and Variables & Factor Loadings \\
\hline Video Content Characteristics & \\
The video content seems engaging (video content example 1) & 0.744 \\
The information video content seems relevant (video content example 1) & 0.819 \\
I like the font used in the video content (video content example 1) & 0.791 \\
I like the colors used in the video content (video content example 1) & 0.749 \\
I like the picture used in the video content (video content example 1) & 0.723 \\
I like that the video content uses the logo (video content example 1) & 0.524 \\
The information contained in the video content is clear (video content & 0.665 \\
example 1) & \\
\hline
\end{tabular}


Table 5. Cont.

\begin{tabular}{cc}
\hline Factors and Variables & Factor Loadings \\
\hline The video content seems engaging (video content example 2) & 0.819 \\
The information video content seems relevant (video content example 2) & 0.770 \\
I like the font used in the video content (video content example 2) & 0.831 \\
I like the colors used in the video content (video content example 2) & 0.796 \\
I like the picture used in the video content (video content example 1) & 0.782 \\
I like that the video content uses the logo (video content example 2) & 0.800 \\
The information contained in the video content is clear (video content & 0.710 \\
example 2) & \\
KMO:0.870; Bartlett: 0.000 &
\end{tabular}

The claims of the video content characteristics have a statistically significant correlation.

Since the results meet all the criteria, several variables were defined, which in general encompass the video content characteristics: video content characteristics (general); video content purpose; video content design; understandability of the video content; memorability of the video content.

The findings of the overall factor analysis of all of the claims suggested that the data is essentially centered around two factors, with an uneven distribution of the statements. The distribution of statements has a random positioning, and the study variables lose structure. In order to be able to analyze the results and test the study model, it was decided not to change the structure and construct the factors according to the procedure already in place.

A factor analysis of the video content examples through the confidence drivers identified new variables for subsequent calculations: quality and informativeness of video content 1 ; fun of video content 1 ; attractiveness of video content 1 ; identity of video content 1 ; quality and informativeness of video content 2 ; fun of video content 2; attractiveness of video content 2; identity of video content 2; overall quality and informativeness of the video content; overall fun of the video content; overall attractiveness of the video content; identity of the overall video content.

A factor analysis of the engagement in the confidence drivers constructed new variables for further consideration: cognitive engagement, emotional engagement and engagement by behavior. Since the results met all the criteria, the engagement as confidence was identified as a single variable that encompasses the overall rating of the confidence on the part of the consumers.

A summary of the findings produced by the factor analysis shows that the variables maintained the same structure and were not changed. For the purpose of a deeper analysis, thirteen new variables are used to analyze the hypotheses raised for the purpose of the survey.

\section{Hypotheses Testing Results}

The interrelations of the variables, their strength and their direction were calculated according to the Spearman correlation coefficient. Table 6 contains the correlation analysis of the four characteristics of the video content and the drivers of consumer confidence in the brand.

An overview of the correlation results presented in Table 6 concluded that all correlations were statistically significant $(p<0.05)$. The strongest link between the variables is in the case of the purpose of the video content and the fun of the video content, for which the Spearman correlation coefficient is 0.930 . The weakest link is between the understandability of the video content and the overall quality and the informativeness, which was rated at 0.484 . 
Table 6. Results of the correlation analysis of the quality and informativeness, and the engagement with the brand-created content on the SMCG.

\begin{tabular}{|c|c|c|c|c|c|c|}
\hline & & & $\begin{array}{l}\text { Overall Quality and } \\
\text { Informativeness of } \\
\text { the Video Content }\end{array}$ & $\begin{array}{l}\text { Overall Fun of } \\
\text { the Video } \\
\text { Content }\end{array}$ & $\begin{array}{l}\text { Attractiveness of } \\
\text { the Video } \\
\text { Content }\end{array}$ & $\begin{array}{c}\text { Overall Identity } \\
\text { of the Video } \\
\text { Content }\end{array}$ \\
\hline \multirow{12}{*}{$\begin{array}{l}\text { Spearman's } \\
\text { rho }\end{array}$} & \multirow{3}{*}{$\begin{array}{l}\text { Purpose } \\
\text { of the video } \\
\text { content }\end{array}$} & $\begin{array}{l}\text { Correlation } \\
\text { Coefficient }\end{array}$ & 0.868 & 0.930 & 0.854 & 0.884 \\
\hline & & Sig. (two-tailed) & 0.000 & 0.000 & 0.000 & 0.000 \\
\hline & & Eil. & 387 & 387 & 387 & 387 \\
\hline & \multirow{3}{*}{$\begin{array}{l}\text { Design } \\
\text { of the video } \\
\text { content }\end{array}$} & $\begin{array}{l}\text { Correlation } \\
\text { Coefficient }\end{array}$ & 0.799 & 0.799 & 0.916 & 0.779 \\
\hline & & Sig. (two-tailed) & 0.000 & 0.000 & 0.000 & 0.000 \\
\hline & & Eil. & 387 & 387 & 387 & 387 \\
\hline & \multirow{3}{*}{$\begin{array}{l}\text { Understandability } \\
\text { of the video } \\
\text { content }\end{array}$} & $\begin{array}{l}\text { Correlation } \\
\text { Coefficient }\end{array}$ & 0.484 & 0.583 & 0.660 & 0.635 \\
\hline & & Sig. (two-tailed) & 0.000 & 0.000 & 0.000 & 0.000 \\
\hline & & No. & 387 & 387 & 387 & 387 \\
\hline & \multirow{3}{*}{$\begin{array}{l}\text { Memorability } \\
\text { of the video } \\
\text { content }\end{array}$} & $\begin{array}{l}\text { Correlation } \\
\text { Coefficient }\end{array}$ & 0.830 & 0.679 & 0.710 & 0.649 \\
\hline & & Sig. (two-tailed) & 0.000 & 0.000 & 0.000 & 0.000 \\
\hline & & Eil. & 387 & 387 & 387 & 387 \\
\hline
\end{tabular}

Furthermore, an analysis of the same type was carried out on the results of the relationships between the overall characteristics of the video content and the trigger of consumer confidence in brands, the quality and the informativeness of the video content and the engagement with the brand-created content in the SMCGs; the fun of the video content and the engagement with the brand-created content in the SMCGs; the attractiveness of the video content and the engagement with the brand-created content in the SMCGs; the identity of the video content and the engagement with the brand-created content in the SMCGs; and the relation between the engagement with the brand-created video content in the SMCGs and the confidence in the brand.

The relationships of all analyzed variables are statistically significant and almost all have high Spearman correlation coefficients, so the hypotheses were tested by way of a regression analysis without removing any of the variables.

Hypothesis $\mathrm{H} 1$ concerns the potential effect of the characteristics of the video content on the drivers of the consumer confidence in the brand. Hypothesis H1 is tested by conducting four analyses, because it concerns various partial hypotheses. Seeking to mitigate the complexity of the results and the analysis of the correlation of the video content example, the regression $\mathrm{H} 1$ analysis was carried out jointly with the variables of the two video content examples (Table 7).

The regression analysis presented in Table 7 presents the analyses of the four drivers of consumer confidence in the brands through the four characteristics of the video content. Dependent variable 1 concerns the overall quality and informativeness of the video content. For the purpose of the analysis, the highest Beta value is 0.445 , which means that the video content purpose has the strongest effect on the quality and the informativeness as compared with the other characteristics. A characteristic close in value is the memorability of the video content, with a Beta coefficient of 0.415 . The $p$-value can suggest that the understandability of the video content does not affect the quality and the informativeness of the video content, because the value is 0.05 (higher than 0.05 ); therefore, hypothesis H1a is refuted. 
Table 7. Results of the multidimensional linear regression analysis of the relation between the characteristics of the video content and the drivers of consumer confidence in the brand.

\begin{tabular}{|c|c|c|c|c|c|c|c|c|}
\hline \multirow{2}{*}{$\begin{array}{l}\text { Dependent } \\
\text { Variable }\end{array}$} & \multirow{2}{*}{$\mathbf{R}^{2}$} & \multicolumn{2}{|c|}{ ANOVA } & \multirow{2}{*}{$\begin{array}{l}\text { Independent } \\
\text { Variable }\end{array}$} & \multicolumn{2}{|c|}{$\begin{array}{l}\text { Non-Standardized } \\
\text { Coefficients }\end{array}$} & \multirow{2}{*}{$\begin{array}{c}\begin{array}{c}\text { Standardized } \\
\text { Coefficient }\end{array} \\
\text { Beta }\end{array}$} & \multirow{2}{*}{$p$-Value } \\
\hline & & F & $p$-Value & & B & $\begin{array}{l}\text { Standard } \\
\text { Deviation }\end{array}$ & & \\
\hline \multirow{4}{*}{$\begin{array}{l}\text { Overall quality and } \\
\text { informativeness of the } \\
\text { video content }\end{array}$} & \multirow{4}{*}{0.869} & \multirow{4}{*}{632.373} & \multirow{4}{*}{0.000} & \multirow{4}{*}{$\begin{array}{l}\text { Purpose of the video content } \\
\text { Design of the video content } \\
\text { Understandability of the } \\
\text { video content } \\
\text { Memorability of the video } \\
\text { content }\end{array}$} & 0.495 & 0.045 & 0.445 & 0.000 \\
\hline & & & & & 0.198 & 0.039 & 0.192 & 0.000 \\
\hline & & & & & -0.070 & 0.036 & -0.057 & 0.053 \\
\hline & & & & & 0.468 & 0.033 & 0.415 & 0.000 \\
\hline \multirow{4}{*}{$\begin{array}{l}\text { Overall fun of the } \\
\text { video content }\end{array}$} & \multirow{4}{*}{0.869} & \multirow{4}{*}{633.158} & \multirow{4}{*}{0.000} & \multirow{4}{*}{$\begin{array}{l}\text { Purpose of the video content } \\
\text { Design of the video content } \\
\text { Understandability of the } \\
\text { video content } \\
\text { Memorability of the video } \\
\text { content }\end{array}$} & 0.977 & 0.043 & 0.907 & 0.000 \\
\hline & & & & & 0.097 & 0.038 & 0.097 & 0.011 \\
\hline & & & & & -0.127 & 0.035 & -0.108 & 0.000 \\
\hline & & & & & 0.030 & 0.032 & 0.027 & 0.354 \\
\hline \multirow{4}{*}{$\begin{array}{l}\text { Attractiveness of the } \\
\text { video content }\end{array}$} & \multirow{4}{*}{0.882} & \multirow{4}{*}{714.559} & \multirow{4}{*}{0.000} & \multirow{4}{*}{$\begin{array}{l}\text { Purpose of the video content } \\
\text { Design of the video content } \\
\text { Understandability of the } \\
\text { video content } \\
\text { Memorability of the video } \\
\text { content }\end{array}$} & 0.292 & 0.043 & 0.257 & 0.000 \\
\hline & & & & & 0.547 & 0.038 & 0.521 & 0.000 \\
\hline & & & & & 0.209 & 0.035 & 0.169 & 0.000 \\
\hline & & & & & 0.075 & 0.032 & 0.065 & 0.021 \\
\hline \multirow{4}{*}{$\begin{array}{l}\text { Overall identity of the } \\
\text { video content }\end{array}$} & \multirow{4}{*}{0.776} & \multirow{4}{*}{330.795} & \multirow{4}{*}{0.000} & \multirow{4}{*}{$\begin{array}{l}\text { Purpose of the video content } \\
\text { Design of the video content } \\
\text { Understandability of the } \\
\text { video content } \\
\text { Memorability of the video } \\
\text { content }\end{array}$} & 0.685 & 0.053 & 0.674 & 0.000 \\
\hline & & & & & 0.061 & 0.046 & 0.065 & 0.186 \\
\hline & & & & & 0.116 & 0.043 & 0.104 & 0.007 \\
\hline & & & & & 0.090 & 0.040 & 0.087 & 0.025 \\
\hline
\end{tabular}

The second dependent variable was the overall fun of the video content. The highest Beta value is 0.907 , which means that in comparison with the other characteristics, the purpose of the video content has the strongest effect on the fun of the video content. Because the memorability for the video content which is materially excessive had a $p$-value of $0.354(>0.05)$, H1b was refuted.

The third dependent variable was the overall attractiveness of the video content. The video content design has the highest Beta value (Beta $=0.521)$; therefore, compared with the other characteristics, the design has a major influence on the attractiveness of the video content. Since design captures the technical video content creation aspects, the effect of this characteristic is evident. The $p$-value in this section of the analysis is appropriate (lower than 0.05); therefore, hypothesis H1c is confirmed.

The last dependent variable examined was the overall attractiveness of the video content. In this context, the video content purpose has the highest B value, i.e., 0.674 , which is more than six times higher than the value of the understandability of the video content ( $\beta=0.104)$. This means that the purpose of the video content is the greatest influencer on the identity of the video content with the consumers. As the $p$-value of the design of the video content exceeds 0.05 , hypothesis $\mathrm{H} 1 \mathrm{~d}$ was refuted.

An overview of the results of the multidimensional linear regression analysis of the relation between the characteristics of the video content and the drivers of the confidence of consumers in the brand led to the conclusion that hypothesis H1, consisting of the partial hypotheses H1a, H1b, H1c and H1d, was partly refuted. The hypothesis was refuted only partially because the study sought to clarify whether all the four characteristics of the video content may affect the drivers of consumer confidence in the brand.

Table 8 contains the results of the multidimensional linear regression analysis of the effect of the drivers of the confidence in the brand on the engagement with the brandcreated video content in the social media community groups. The analysis presented in Table 8 contains the hypotheses $\mathrm{H} 2-\mathrm{H} 5$ together with the dependent partial hypotheses. 
Table 8. Results of the multidimensional linear regression analysis of the effect of the drivers of the confidence in the brand on the engagement with the brand-created video content in the social media community groups.

\begin{tabular}{|c|c|c|c|c|c|c|c|c|}
\hline \multirow{2}{*}{$\begin{array}{l}\text { Dependent } \\
\text { Variable }\end{array}$} & \multirow{2}{*}{$\mathbf{R}^{2}$} & \multicolumn{2}{|c|}{ ANOVA } & \multirow{2}{*}{$\begin{array}{l}\text { Independent } \\
\text { Variable }\end{array}$} & \multicolumn{2}{|c|}{$\begin{array}{l}\text { Non-Standardized } \\
\text { Coefficients }\end{array}$} & \multirow{2}{*}{$\begin{array}{c}\begin{array}{c}\text { Standardized } \\
\text { Coefficient }\end{array} \\
\text { Beta }\end{array}$} & \multirow{2}{*}{$p$-Value } \\
\hline & & $\mathbf{F}$ & $p$-Value & & B & $\begin{array}{l}\text { Standard } \\
\text { Deviation }\end{array}$ & & \\
\hline \multirow{4}{*}{$\begin{array}{l}\text { Cognitive } \\
\text { engagement }\end{array}$} & \multirow{4}{*}{0.559} & \multirow{4}{*}{120.864} & \multirow{4}{*}{0.000} & $\begin{array}{l}\text { Overall quality and informativeness } \\
\text { of the video content }\end{array}$ & 0.246 & 0.062 & 0.305 & 0.000 \\
\hline & & & & Overall fun of the video content & -0.388 & 0.070 & -0.466 & 0.000 \\
\hline & & & & Attractiveness of the video content & 0.319 & 0.060 & 0.403 & 0.000 \\
\hline & & & & Overall identity of the video content & 0.457 & 0.063 & 0.519 & 0.000 \\
\hline \multirow{4}{*}{$\begin{array}{l}\text { Emotional } \\
\text { engagement }\end{array}$} & \multirow{4}{*}{0.528} & \multirow{4}{*}{106.878} & \multirow{4}{*}{0.000} & $\begin{array}{l}\text { Overall quality and informativeness } \\
\text { of the video content }\end{array}$ & 0.167 & 0.065 & 0.205 & 0.000 \\
\hline & & & & Overall fun of the video content & -0.457 & 0.073 & -0.546 & 0.000 \\
\hline & & & & Attractiveness of the video content & 0.435 & 0.062 & 0.546 & 0.000 \\
\hline & & & & Overall identity of the video content & 0.457 & 0.066 & 0.516 & 0.000 \\
\hline \multirow{4}{*}{$\begin{array}{l}\text { Engagement } \\
\text { by behavior }\end{array}$} & \multirow{4}{*}{0.549} & \multirow{4}{*}{116.047} & \multirow{4}{*}{0.000} & $\begin{array}{l}\text { Overall quality and informativeness } \\
\text { of the video content }\end{array}$ & 0.188 & 0.077 & 0.190 & 0.015 \\
\hline & & & & Overall fun of the video content & 0.122 & 0.087 & 0.120 & 0.163 \\
\hline & & & & Attractiveness of the video content & 0.092 & 0.074 & 0.095 & 0.217 \\
\hline & & & & Overall identity of the video content & 0.414 & 0.079 & 0.383 & 0.000 \\
\hline
\end{tabular}

The analysis of the multidimensional linear regression analysis of the effect of the drivers of the confidence in the brand on the engagement with the brand-created video content in the social media community groups, as presented in Table 8, examines three dependent variables: cognitive engagement, emotional engagement and engagement by behavior. The first dependent variable is cognitive engagement. Dependent variable 1 concerns the overall quality and informativeness of the video content. The highest Beta value is 0.519 ; therefore, the overall identity of the video content produces the most significant effect on the cognitive engagement. The second beta in terms of size was the overall attractiveness of the video content, with a value of 0.403 . The $p$-value shows that all the values were below 0.05 , and therefore, all the variables affect the cognitive engagement. This was corroborated by the hypotheses $\mathrm{H} 2 \mathrm{a}, \mathrm{H} 3 \mathrm{a}, \mathrm{H} 4 \mathrm{a}$ and $\mathrm{H} 5 \mathrm{a}$.

The next dependent variable, analyzed and presented in Table 8, was emotional engagement. The highest Beta value was the overall attractiveness of the video content ( $\beta=0.546)$. The other highest Beta value that is close to the first value is the overall identity of the video content $(\beta=0.516)$. The $p$-value of all the independent variables was below 0.05 ; therefore, all the variables affect the emotional engagement. In view of the existing effect, the hypotheses $\mathrm{H} 2 \mathrm{~b}, \mathrm{H} 3 \mathrm{~b}, \mathrm{H} 4 \mathrm{~b}$ and $\mathrm{H} 5 \mathrm{~b}$ were confirmed.

Among the finding of the analysis of the dependent variable of engagement by behavior, the highest Beta value is that of the overall video content identity $(\beta=0.383)$, which reflects the most prominent effect on the engagement by behavior. In only two independent variables, the quality and the informativeness variables, the $p$-value was below 0.05 ; therefore, only the hypotheses $\mathrm{H} 2 \mathrm{c}$ and $\mathrm{H} 5 \mathrm{c}$ were confirmed. Because of the low $p$-value, the overall fun of the video content and the overall video content do not affect the engagement by behavior; therefore, the hypotheses $\mathrm{H} 3 \mathrm{c}$ an $\mathrm{H} 4 \mathrm{c}$ were refuted.

A summary of the results of the multidimensional linear regression analysis of the effect of the drivers of the confidence in the brand on the engagement with the brandcreated video content in the social media community groups, as presented in Table 8, led to the conclusion that the hypotheses $\mathrm{H} 2$ and $\mathrm{H} 5$ were confirmed, and the hypotheses $\mathrm{H} 3$ and $\mathrm{H} 4$ were confirmed partly.

The last multidimensional linear regression analysis concerned the effect of the engagement with the brand-created video content in social media community groups on the confidence in the brand (H6) (Table 9). The analysis sought to establish the effect of the cognitive, emotional and behavioral engagement on the consumer confidence in the brand. 
Table 9. The results of the last multidimensional linear regression analysis of the relationship between the engagement with the brand-created video content in social media community groups and the confidence in the brand.

\begin{tabular}{|c|c|c|c|c|c|c|c|c|}
\hline \multirow{2}{*}{$\begin{array}{l}\text { Dependent } \\
\text { Variable }\end{array}$} & \multirow{2}{*}{$\mathbf{R}^{2}$} & \multicolumn{2}{|c|}{ ANOVA } & \multirow{2}{*}{$\begin{array}{l}\text { Independent } \\
\text { Variable }\end{array}$} & \multicolumn{2}{|c|}{$\begin{array}{l}\text { Non-Standardized } \\
\text { Coefficients }\end{array}$} & \multirow{2}{*}{$\begin{array}{c}\begin{array}{c}\text { Standardized } \\
\text { Coefficient }\end{array} \\
\text { Beta }\end{array}$} & \multirow{2}{*}{$p$-Value } \\
\hline & & $\mathbf{F}$ & $p$-Value & & B & $\begin{array}{c}\text { Standard } \\
\text { Deviation }\end{array}$ & & \\
\hline \multirow{3}{*}{$\begin{array}{l}\text { Engagement as } \\
\text { confidence }\end{array}$} & \multirow{3}{*}{0.836} & \multirow{3}{*}{651.405} & \multirow{3}{*}{0.000} & Cognitive engagement & 0.213 & 0.083 & 0.193 & 0.011 \\
\hline & & & & Emotional engagement & 0.215 & 0.078 & 0.196 & 0.006 \\
\hline & & & & Engagement by behavior & 0.549 & 0.026 & 0.611 & 0.000 \\
\hline
\end{tabular}

For the purpose of the analysis, the highest Beta value is 0.611 , which means that the engagement by behavior plays the most significant role on the confidence. The $p$-value shows that all the three independent variables affect the confidence, because their value was below 0.05 . The analysis leads to the conclusion that hypothesis $\mathrm{H} 6$ is confirmed.

Table 10 was drawn up to present a summary of the analyses of all the hypotheses and show the results obtained.

Table 10. Results of an empirical study of the hypotheses on the influence of the video content created by a brand on consumer confidence in social media community groups.

\begin{tabular}{|c|c|c|}
\hline Hypothesis Summary & Hypothesis & Results \\
\hline $\mathrm{H} 1$ & $\begin{array}{l}\text { The characteristics of video content affect the drivers of consumer } \\
\text { confidence in the brand }\end{array}$ & Partly confirmed \\
\hline $\mathrm{H} 1 \mathrm{a}$ & $\begin{array}{c}\text { The characteristics of video content affect the quality and the } \\
\text { informativeness of the video content }\end{array}$ & Rejected \\
\hline $\mathrm{H} 1 \mathrm{~b}$ & The characteristics of video content affect its entertainment qualities & Rejected \\
\hline $\mathrm{H} 1 \mathrm{c}$ & The characteristics of video content affect its attractiveness & Confirmed \\
\hline H1d & The characteristics of video content affect its identity & Rejected \\
\hline $\mathrm{H} 2$ & $\begin{array}{l}\text { The quality and the informativeness of the video content affect the } \\
\text { involvement of the content created by a brand within the social network } \\
\text { community groups }\end{array}$ & Confirmed \\
\hline $\mathrm{H} 2 \mathrm{a}$ & $\begin{array}{l}\text { The quality and the informativeness of the video content affect the } \\
\text { cognitive involvement }\end{array}$ & Confirmed \\
\hline $\mathrm{H} 2 \mathrm{~b}$ & $\begin{array}{c}\text { The quality and the informativeness of the video content affect the } \\
\text { emotional involvement }\end{array}$ & Confirmed \\
\hline $\mathrm{H} 2 \mathrm{c}$ & $\begin{array}{l}\text { The quality and the informativeness of the video content affect the } \\
\text { behavioral involvement }\end{array}$ & Confirmed \\
\hline $\mathrm{H} 3$ & $\begin{array}{l}\text { The fun of the video content affects the involvement in the content created } \\
\text { by a brand within the social network community groups }\end{array}$ & Partly confirmed \\
\hline $\mathrm{H} 3 \mathrm{a}$ & The fun of the video content affects the cognitive involvement & Confirmed \\
\hline $\mathrm{H} 3 \mathrm{~b}$ & The fun of video content affects the emotional involvement & Confirmed \\
\hline $\mathrm{H} 3 \mathrm{c}$ & The fun of the video content affects the behavioral involvement & Rejected \\
\hline $\mathrm{H} 4$ & $\begin{array}{l}\text { The attractiveness of the video content affects the involvement in the } \\
\text { content created by a brand within the social network community groups }\end{array}$ & Partly confirmed \\
\hline $\mathrm{H} 4 \mathrm{a}$ & The attractiveness of the video content affects the cognitive involvement & Confirmed \\
\hline $\mathrm{H} 4 \mathrm{~b}$ & The attractiveness of the video content affects the emotional involvement & Confirmed \\
\hline $\mathrm{H} 4 \mathrm{c}$ & The fun of the video content affects the behavioral involvement & Rejected \\
\hline H5 & $\begin{array}{l}\text { The identity of the video content affects the involvement in the content } \\
\text { created by a brand within the social network community groups }\end{array}$ & Confirmed \\
\hline $\mathrm{H} 5 \mathrm{a}$ & The identity of the video content affects the cognitive involvement & Confirmed \\
\hline $\mathrm{H} 5 \mathrm{~b}$ & The identity of the video content affects the emotional involvement & Confirmed \\
\hline $\mathrm{H} 5 \mathrm{c}$ & The identity of the video content affects the behavioral involvement & Confirmed \\
\hline $\mathrm{H} 6$ & $\begin{array}{l}\text { Engagement with the video content created by a brand within social media } \\
\text { community groups affect the confidence in the brand }\end{array}$ & Confirmed \\
\hline
\end{tabular}

The findings of the multidimensional linear regression analysis confirmed three principal and eleven partial hypotheses. Three principal hypotheses were partly confirmed, while five partial hypotheses were rejected. 


\section{Discussion and Conclusions}

The outcomes confirmed the importance of video content in building trust in brand and consumer engagement in SMCGs. The findings of the survey also confirmed a strong relationship between the engagement of the consumer and the confidence in the brand in social medial community groups. The results of the survey also showed that for similar studies in the future, the consumer engagement can be treated as a proxy variable when assessing the satisfaction of a brand in social medial community groups. Part of the hypotheses were confirmed only partially, which shows the necessity of additional studies in the area that are designed to boost the understanding the confidence and engagement within social media community groups. The hypothesis concerning the potential effect of the characteristics of the video content on the drivers of the consumer confidence in the brand was confirmed only partially. The hypothesis disclosed that for the purpose of the study, all the video content characteristics could affect the attractiveness dimension only. Another hypothesis that was also confirmed, i.e., the effect of the fun of the video content on the engagement, also showed that fun content does not necessarily lead to consumer engagement behavior (comment, share or press 'Like'). The latest partially confirmed hypothesis revealed that technically attractive content does not necessarily lead to consumer engagement behavior. With all the other hypotheses confirmed, it may be concluded that the video content can affect the user to develop confidence in the brand. Thus, the analysis of the characteristics of the video content, the drivers of consumer confidence in the brand, engagement with the brand-created video content on the SMCG and the confidence in the brand led to the conclusion that the video content characteristics examined as part of the study may affect the attractiveness, which can lead to cognitive and emotional engagement. The analysis showed that all the three types of engagement may point to the confidence in the brand on the part of the user. Thus, the brand-created video content matching the drivers of confidence in the brand may facilitate emotional or behavioral engagement, which can be an indication of consumer confidence in the brand.

There are some limitations in the present study. The research was based on SMCGs on Facebook. Adding other channels, such as Instagram, LinkedIn, Twitter, etc., could provide additional insights or slightly alter the results. Changing the industry from apparel to other industries, for example, luxurious perfume or cheap FMCG products, may also provide different results, as proved by Santos, Coelho \& Rita [31].

In the future, it would be scientifically sound to more thoroughly investigate the relationship between the characteristics of the visual context and variables such as video content quality, fun, identity and engagement by behavior. Such follow-up studies are specifically appropriate as the study covered by the present paper did not confirm the relations discussed above, though the relations were directly referred to in other studies [25]. The indication that moderating variables influence the results would enrich marketing knowledge about consumer trust in brands in SMCGs.

Author Contributions: Conceptualization, L.K. and E.R.; methodology, L.K.; formal analysis, L.K.; investigation, M.M.; resources, A.V.; data curation, L.K.; writing—original draft preparation, M.M.; writing-review and editing, E.R.; visualization, A.V. All authors have read and agreed to the published version of the manuscript.

Funding: This research received no external funding.

Institutional Review Board Statement: Not applicable.

Informed Consent Statement: Not applicable.

Conflicts of Interest: The authors declare no conflict of interest.

\section{References}

1. Wang, T. Social identity dimensions and consumer behavior in social media. Asia Pac. Manag. Rev. 2017, 22, 45-51. [CrossRef]

2. Voramontri, D.; Klieb, L. Impact of social media on consumer behaviour. Int. J. Inf. Decis. Sci. 2019, 11, $209-233$. 
3. Pi, S.M.; Chou, C.H.; Liao, H.L. A study of Facebook Groups members' knowledge sharing. Comput. Hum. Behav. 2013, 29, 1971-1979. [CrossRef]

4. Shareef, M.A.; Mukerji, B.; Dwivedi, Y.K.; Rana, N.P.; Islam, R. Social media marketing: Comparative effect of advertisement sources. J. Retail. Consum. Serv. 2019, 46, 58-69. [CrossRef]

5. Ancillai, C.; Terho, H.; Cardinali, S.; Pascucci, F. Advancing social media driven sales research: Establishing conceptual foundations for B-to-B social selling. Ind. Mark. Manag. 2019, 82, 293-308. [CrossRef]

6. Siudikienè, D. Vartotoju ìsitraukimas i prekès ženklo bendruomenę. Inf. Moksl. 2016, 74, 50-69. [CrossRef]

7. Euromonitor Economies and Consumers Annual Data. 2020. Available online: https://portal.euromonitor.com/portal/ statisticsevolution/index (accessed on 10 March 2021).

8. Chu, S.C. Viral advertising in social media: Participation in Facebook groups and responses among college-aged users. J. Interact. Advert. 2011, 12, 30-43. [CrossRef]

9. Lou, C.; Yuan, S. Influencer marketing: How message value and credibility affect consumer trust of branded content on social media. J. Interact. Advert. 2019, 19, 58-73. [CrossRef]

10. Han, S.L.; Sung, H.S. Industrial brand value and relationship performance in business markets-A general structural equation model. Ind. Mark. Manag. 2008, 37, 807-818. [CrossRef]

11. Li, H.; Lo, H.Y. Do you recognize its brand? The effectiveness of online in-stream video advertisements. J. Advert. 2015, 44, 208-218. [CrossRef]

12. Anderson, B. B2B Marketers Leverage Interactive Content for Relevant Buyer Experiences. Demand Gen Report. 2015. Available online: https://www.demandgenreport.com/features/industry-insights/b2b-marketers-leverage-interactive-content-forrelevant-buyer-experiences (accessed on 14 December 2020).

13. Kim, D.H.; Spiller, L.; Hettche, M. Analyzing media types and content orientations in Facebook for global brands. J. Res. Interact. Mark. 2015, 9, 4-30. [CrossRef]

14. Holzner, S. Facebook Marketing: Leverage Social Media to Grow Your Business; Pearson Education: London, UK, 2008.

15. Hollebeek, L.D.; Macky, K. Digital content marketing's role in fostering consumer engagement, trust, and value: Framework, fundamental propositions, and implications. J. Interact. Market. 2019, 45, 27-41. [CrossRef]

16. Davis, R.; Piven, I.; Breazeale, M. Conceptualizing the brand in social media community: The five sources model. J. Retail. Consum. Serv. 2014, 21, 468-481. [CrossRef]

17. Myrick, J.G.; Holton, A.E.; Himelboim, I.; Love, B. \#Stupidcancer: Exploring a typology of social support and the role of emotional expression in a social media community. Health Commun. 2016, 31, 596-605.

18. Sirola, A.; Kaakinen, M.; Savolainen, I.; Oksanen, A. Loneliness and online gambling-community participation of young social media users. Comput. Hum. Behav. 2019, 95, 136-145. [CrossRef]

19. Wongkitrungrueng, A.; Assarut, N. The role of live streaming in building consumer trust and engagement with social commerce sellers. J. Bus. Res. 2020, 117, 543-556. [CrossRef]

20. Liu, L.; Lee, M.K.; Liu, R.; Chen, J. Trust transfer in social media brand communities: The role of consumer engagement. Int. J. Inf. Manag. 2018, 41, 1-13. [CrossRef]

21. Harridge-March, S. Can the building of trust overcome consumer perceived risk online? Mark. Intell. Plann. 2006, 24, 746-761. [CrossRef]

22. Koh, J.; Kim, Y.G.; Kim, Y.G. Sense of virtual community: A conceptual framework and empirical validation. Int. J. Electron. Commer. 2003, 8, 75-94. [CrossRef]

23. Okoli, D.C. Visual Content, Social Commerce and Consumer; Northumbria University: Newcastle upon Tyne, UK, 2016.

24. Hajli, M.N. A Study of the Impact of Social Media on Consumers. Int. J. Mark. Res. 2014, 56, 387-404. [CrossRef]

25. Pathak, B.; Garfinkel, R.; Gopal, R.D.; Venkatesan, R.; Yin, F. Empirical analysis of the impact of recommender systems on sales. J. Manag. Inf. Syst. 2010, 27, 159-188. [CrossRef]

26. Kim, Y.A.; Ahmad, M.A. Trust, distrust and lack of confidence of users in online social media-sharing communities. Knowl.-Based Syst. 2013, 37, 438-450. [CrossRef]

27. Kang, J. Social Media Marketing in the Hospitality Industry: The Role of Benefits in Increasing Brand Community Participation and the Impact of Participation on Consumer Trust and Commitment toward Hotel and Restaurant Brands. Ph.D. Thesis, Iowa State University, Ames, IA, USA, 2011. Available online: https:/ /lib.dr.iastate.edu/etd/10447 (accessed on 3 December 2020).

28. Laroche, M.; Habibi, M.R.; Richard, M.O. To be or not to be in social media: How brand loyalty is affected by social media? Int. J. Inf. Manag. 2013, 33, 76-82. [CrossRef]

29. Habibi, M.R.; Laroche, M.; Richard, M.O. The roles of brand community and community engagement in building brand trust on social media. Comput. Hum. Behav. 2014, 37, 152-161. [CrossRef]

30. Jibril, A.B.; Kwarteng, M.A.; Chovancova, M.; Pilik, M. The impact of social media on consumer-brand loyalty: A mediating role of online based-brand community. Cogent Bus. Manag. 2019, 6, 1673640. [CrossRef]

31. Santos, Z.R.; Coelho, P.S.; Rita, P. Fostering Consumer-Brand Relationships through social media brand communities. J. Mark. Commun. 2021. [CrossRef]

32. Wang, X.; Wang, Y.; Lin, X.; Abdullat, A. The dual concept of consumer value in social media brand community: A trust transfer perspective. Int. J. Inf. Manag. 2021, 59, 102319. [CrossRef] 
33. Zhang, Z.; Gu, C. Effects of consumer social interaction on trust in online group-buying contexts: An empirical study in China. J. Electron. Commer. Res. 2015, 16, 1.

34. Zailskaitè-Jakšte, L. Consumer Engagement Behaviour in Social Media Communication Impact on Brand Equity. Ph.D. Thesis, Kauno Technologijos Universitetas, Kaunas, Lithuania, 2018.

35. Danaitis, K.S.; Usovaitè, A. Vizualinė Komunikacija: Kompiuterinès Grafikos Irankiu Taikymas, Kuriant Logotipa. Coactivity/Santalka 2012, 20, 78-90. [CrossRef]

36. Dunay, P.; Krueger, R. Facebook Marketing for Dummies; John Wiley and Sons: Hoboken, NJ, USA, 2009.

37. Jakic, A.; Wagner, M.O.; Meyer, A. The impact of language style accommodation during social media interactions on brand trust. J. Serv. Manag. 2017, 28, 418-441. [CrossRef]

38. Sharma, R.; Alavi, S.; Ahuja, V. Generating trust using Facebook-A study of 5 online apparel brands. Procedia Comput. Sci. 2017, 122, 42-49. [CrossRef]

39. Busser, J.A.; Shulga, L.V. Involvement in consumer-generated advertising. Int. J. Contemp. Hosp. Manag. 2019, 31, 1763-1784. [CrossRef]

40. Hinson, R.; Boateng, H.; Renner, A.; Kosiba, J.P.B. Antecedents and consequences of customer engagement on Facebook. J. Res. Interact. Mark. 2019, 13, 204-226. [CrossRef]

41. Statista-The Statistics Portal for Market Data, Market Research and Market Studies. Available online: https://www.utu.fi/en/ news/news/statista-the-statistics-portal-for-market-data-market-research-and-market-studies (accessed on 21 March 2019).

42. Soni, N.; Verghese, M. Analyzing the Impact of Online Brand Trust on Sales Promotion and Online Buying Decision. IUP J. Mark. Manag. 2018, 11, 234-254.

43. Engage and Support Customers on Social Media-NapoleonCat. Available online: https://napoleoncat.com (accessed on 4 January 2020). 